REVIEW

\title{
The management of gestational diabetes
}

\author{
N Wah Cheung \\ Centre for Diabetes and \\ Endocrinology Research, Westmead \\ Hospital, and University of Sydney, \\ NSW, Australia
}

\begin{abstract}
The incidence of gestational diabetes is increasing. As gestational diabetes is associated with adverse pregnancy outcomes, and has long-term implications for both mother and child, it is important that it is recognized and appropriately managed. This review will examine the pharmacological options for the management of gestational diabetes, as well as the evidence for blood glucose monitoring, dietary and exercise therapy. The medical management of gestational diabetes is still evolving, and recent randomized controlled trials have added considerably to our knowledge in this area. As insulin therapy is effective and safe, it is considered the gold standard of pharmacotherapy for gestational diabetes, against which other treatments have been compared. The current experience is that the short acting insulin analogs lispro and aspart are safe, but there are only limited data to support the use of long acting insulin analogs. There are randomized controlled trials which have demonstrated efficacy of the oral agents glyburide and metformin. Whilst short-term data have not demonstrated adverse effects of glyburide and metformin on the fetus, and they are increasingly being used in pregnancy, there remain long-term concerns regarding their potential for harm.
\end{abstract}

Keywords: gestational diabetes, insulin, oral antidiabetic agents, pregnancy, type 2 diabetes

\section{Background}

Gestational diabetes (GDM) is defined as "carbohydrate intolerance with onset or first recognition during pregnancy". ${ }^{1}$ Large studies have found that GDM occurs in $2.2 \%-8.8 \%$ of pregnancies, depending on the ethnic mix of the population and the criteria used for diagnosis. ${ }^{2}$ In some specific populations however, the incidence can be considerably higher. The incidence of GDM is increasing, in parallel to the increase in type 2 diabetes. Essentially, women at risk of type 2 diabetes are at risk of GDM.

During pregnancy, an increase in insulin resistance occurs. Euglycemia is maintained through a compensatory increase in insulin secretion. The key factor which results in the development of gestational diabetes appears to be a failure to compensate with increased insulin secretion. ${ }^{3}$ As the increase in insulin resistance is greatest in the third trimester, GDM usually develops going into this period. Therefore, screening for GDM usually occurs around 24-28 weeks into the pregnancy. The diagnosis is made with an oral glucose tolerance test, though the criteria vary around the world (Table 1). Risk factors for the development of GDM include obesity, older age, family history, previous history of GDM or poor obstetric outcomes, ethnicity, polycystic ovary syndrome and as more recently noted, hypertension. ${ }^{4,5}$

The major significance of GDM is that it is associated with adverse pregnancy outcomes. Macrosomia, shoulder dystocia with its attendant risks of brachial plexus injury and clavicle fracture, and neonatal hypoglycemia are the serious complications which most commonly occur. ${ }^{6-11}$ Jaundice, polycythemia, respiratory distress, and hypocalcemia have also been reported. Additionally, there are some data that suggest an increase in fetal malformation and perinatal mortality. ${ }^{7,12-15}$ The above risks can be minimized with good glycemic control and judicious obstetric care. Cesarean sections are also more common, and GDM is associated with a higher risk of pre-eclampsia. ${ }^{9-11}$ 
Table I Diagnostic criteria for GDM

\begin{tabular}{lllllll}
\hline & Glucose load & \multicolumn{2}{l}{ Glucose tolerance test $\mathbf{( m m o l / L )}$} & Abnormal values for diagnosis \\
\cline { 3 - 5 } & & Fasting & I hour & $\mathbf{2}$ hours & $\mathbf{3}$ hours & \\
\hline ADA & $75 \mathrm{~g}$ & 5.3 & 10 & 8.6 & 7.8 & Two or more \\
& $100 \mathrm{~g}$ & 5.3 & 10 & 8.6 & Two or more \\
ADIPS & $75 \mathrm{~g}$ & 5.5 & & 8.0 & One \\
CDA & $75 \mathrm{~g}$ & 5.3 & 10.6 & 8.9 & Two or more $=$ GDM \\
WHO & $75 \mathrm{~g}$ & & & & One value $=$ IGT of pregnancy \\
\hline
\end{tabular}

Abbreviations: ADA, American Diabetes Association; ADIPS, Australasian Diabetes in Pregnancy Society; CDA, Canadian Diabetes Association; GDM, gestational diabetes mellitus; WHO, World Health Organisation.

Exposure of the fetus to hyperglycemia may also predispose the child to a diabetes phenotype in later life. This has been elegantly demonstrated by the long-term follow-up of the offspring of Pima Indian mothers. ${ }^{16,17}$ Offspring who were born to mothers who were already diabetic when pregnant had a $45 \%$ likelihood of type 2 diabetes by the age of 20-24, whereas it was $8.6 \%$ amongst those with mothers who only developed diabetes after pregnancy (ie, were prediabetic). Amongst sibships discordant for exposure to hyperglycemia, the sibling exposed to hyperglycemia had a considerably higher risk of subsequent diabetes, suggesting that genetic factors were not predominantly responsible for the difference in diabetes incidence. Since then, numerous other observational studies have shown that the offspring of diabetic pregnancies have a higher risk of developing a diabetes phenotype. ${ }^{18,19}$ There is also concern that this leads to an intergenerational effect, with GDM promoting diabetes in the offspring, with perpetuation of the vicious cycle when the offspring herself develops GDM, thereby predisposing the grandchild to the development of diabetes as well. ${ }^{20}$ It is unknown however, what degree of hyperglycemia, or indeed if it is related metabolic disturbances, which increases the risk of diabetes to the offspring.

Additionally, the diagnosis of GDM indicates that the mother has a predisposition to diabetes. In most cases, this is type 2 diabetes. In the longest follow-up of women who have had GDM $36 \%$ of women had developed diabetes within $22-28$ years (by WHO criteria). ${ }^{21}$ This was in a predominantly white population in Boston from the 1960s. Evidence from more contemporary populations is that the likelihood of subsequent diabetes may be substantially higher. ${ }^{22}$ Women who have had GDM account for a significant burden of the population prevalence of diabetes. It has been estimated that up to one third of women with diabetes, had a GDM pregnancy earlier in their life, ${ }^{2}$ though this was not evident in a recent survey of women with type 2 diabetes. ${ }^{23}$
This review will focus on the medical management of GDM, in particular self monitoring of blood glucose and diabetes education, dietary therapy and physical activity, pharmacotherapy, and post-partum management. For an excellent discussion of the obstetric management of GDM, I will refer the reader to the review by Conway. ${ }^{24}$

\section{Diabetes education, self-monitoring of blood glucose, dietary therapy, and exercise}

Self-care is an important component of the management of GDM. Therefore it is commonplace for the diabetes care team to provide the women with information and education to facilitate self-care. This includes information regarding GDM, self-monitoring of blood glucose, dietary counseling, and advice regarding healthy lifestyle measures post-partum. The involvement of a dietician and diabetes educator experienced in the care of women with GDM will facilitate these areas of management.

\section{Blood glucose monitoring}

Women with GDM should perform home blood glucose monitoring. Blood glucose levels are usually monitored in the fasting state and 1-2 hours after meals. Treatment to post-prandial targets results in superior pregnancy outcomes compared to pre-prandial targets. ${ }^{25}$ The recommended treatment targets vary from country to country (Table 2). These are largely consensus-based as the risk of complications is continuous and there are no obvious thresholds above which the risk markedly increases.

The initial intervention usually entails dietary advice, individualized if possible, and given by a dietitian. Lifestyle measures can provide adequate control in the majority of cases. If glucose targets are not adequately met by lifestyle measures, and perhaps a review of dietary intake, then 
pharmacotherapy should be introduced. This usually means the commencement of insulin.

Rather than basing the need for insulin on glycemic parameters alone, some have advocated the combined use of ultrasound assessment of fetal abdominal circumference in combination with blood glucose levels. When the fetal abdominal circumference was $<70$ th percentile, a higher glucose threshold for initiating insulin therapy did not result in an increase in fetal morbidity or macrosomia. ${ }^{26}$ This protocol allowed more women to avoid insulin therapy.

\section{Dietary therapy}

It is generally accepted that dietary therapy is the cornerstone of treatment of GDM. Therefore all women with GDM should receive counseling from a specialist dietitian. Recommendations are individualized after a dietary assessment of each patient. The aim is to achieve normoglycemia whilst providing the required nutrients for normal fetal growth and maternal health. A secondary aim is to prevent excessive maternal weight gain, particularly in women who are overweight or have gained excess weight in pregnancy.

There are few trials examining the efficacy of dietary therapy for GDM, However, a cluster randomized controlled study has provided support for Medical Nutrition Therapy (MNT) for GDM, as recommended by the American Diabetes Association (ADA) (2004). In this study, 215 women with GDM were seen at sites randomized to deliver either MNT or standard care. ${ }^{27}$ Fewer subjects in the MNT group required insulin $(24.6 \%$ vs $31.7 \%, \mathrm{p}=0.05)$ and there was a trend to fewer women having a glycated hemoglobin $\left(\mathrm{Hb}_{\mathrm{Alc}}\right)>6 \%(8.1 \%$ vs $13.6 \%, \mathrm{p}=0.25)$. The ADA states that all women should receive individualized counseling to provide adequate calories and nutrients to meet the needs of pregnancy and consistent with the blood glucose goals (fasting $\leq 105 \mathrm{mg} / \mathrm{dl}[5.8 \mathrm{mmol} / \mathrm{L}], 1 \mathrm{hr} \leq 155 \mathrm{mg} / \mathrm{dl}$ [8.6 mmol/L], and $2 \mathrm{hrs} \leq 130 \mathrm{mg} / \mathrm{dl}[7.2 \mathrm{mmol} / \mathrm{L}])$. For obese women, a $30 \%-33 \%$ calorie restriction to approximately $25 \mathrm{kcal} / \mathrm{kg}$ actual weight per day is recommended. Carbohydrate should be restricted to $35 \%-40 \%$ of calories.

There are also data to support low carbohydrate diets in pregnancy, and for the carbohydrate to be of low glycemic index. In a nonrandomized study, women with GDM on a diet comprising less than $42 \%$ carbohydrate, had lower post-prandial glucose levels, were less likely to require insulin, and had a lower incidence of large for gestational age. ${ }^{28}$ A small study which randomized pregnant women to low glycemic index (GI) or high GI diets found that the former resulted in lower glucose levels, a blunting of the pregnancy associated rise in insulin resistance, and lower birthweight. ${ }^{29}$ In another study of GI, women assigned to a low GI diet during pregnancy gave birth to infants who were lighter $(3408 \pm 78 \mathrm{~g}$ vs $3644 \pm 90 \mathrm{~g})$ and had a lower incidence of large for gestational age, compared to women given a high GI diet. ${ }^{30}$ Both diets comprised 55\% carbohydrate. Whilst the latter studies were not specifically performed in women with GDM, they suggest that the concept of GI is valid in pregnancy, and it would be appropriate to recommend low GI carbohydrate to women with GDM.

Additional dietary measures are usually based upon the general recommendations for diabetes mellitus. A reduction in simple carbohydrates and fat intake is advisable. Emphasis is given to spreading the dietary intake over six meals daily, with three main meals and three snacks, in order to avoid large carbohydrate loads at any time. Except for saccharin, which can cross the placenta and is therefore not recommended, other noncaloric sweeteners may be used in moderation.

\section{Physical activity}

In people with type 2 diabetes, there is ample evidence that regular physical activity enhances insulin sensitivity, facilitates weight loss, and thereby improves glucose control. Several small studies have examined whether regular exercise is also beneficial in the management of GDM JovanavicPetersen randomized 19 women with GDM to a regime of diet alone, or diet with 20 minutes of supervised aerobic training three days per week for six weeks. ${ }^{31}$ This modest amount of physical activity resulted in lower fasting glucose levels, lower glucose responses to a glucose challenge, and a lower $\mathrm{Hb}_{\mathrm{Alc}}$. Another study randomized 29 women with GDM to 30 minutes of exercise at $70 \%$ estimated maximal heart rate, 3-4 times per week, or control. ${ }^{32}$ There was a trend to improved glucose levels in those who exercised, which did not reach significance. There were no differences in neonatal outcomes. Measures of cardiorespiratory fitness however, improved. A study of 32 women randomized to circuit type exercise three times a week or control, found that resistance training resulted in lower postprandial glucose levels, and a delay in the requirement of insulin. ${ }^{33}$ Amongst women with a prepregnancy $\mathrm{BMI}>25$, those who were in the exercise arm were less likely to require insulin.

Therefore, it seems reasonable to recommend that when there is no medical or obstetric contraindication, women with GDM should maintain a sensible level of light and moderate intensity physical activity until the latter stages of the pregnancy. The above studies provide reassurance 
that moderate intensity activities such as walking for 20-30 minutes each day, and attendance at antenatal exercise classes can be safely encouraged, and that modest improvements in glycemic control might be achieved.

\section{Insulin therapy for gestational diabetes}

When treatment targets are not achieved by dietary means, then insulin is required. A basal-bolus regimen of insulin gives the most effective glucose control, and produces better fetal outcomes than a twice daily regime. ${ }^{34}$ Prandial fast-acting insulin is administered to control post-prandial hyperglycemia, and bedtime basal insulin is given if there is fasting hyperglycemia. In some cases, an additional morning injection of basal insulin may further improve glycemic control. As the level of insulin resistance varies from person to person, it is common practice to commence the woman on small doses of insulin, and then to increase the doses at frequent intervals until target glucose levels are attained.

The required dosage of insulin usually increases gradually over the third trimester of pregnancy. Towards the end of the pregnancy, insulin requirements can drop. This may be an early indicator of placental insufficiency. Frequent review and titration of the insulin dosage is recommended. Unlike the situation for women with pre-existing type 1 diabetes however, significant hypoglycemia is uncommon in women with insulin-treated GDM. Nonetheless the woman should be advised regarding appropriate hypoglycemia prevention and management measures.

For many years, fast-acting (regular) insulin, and intermediate-acting (isophane) insulin have been the preferred insulins for the treatment of GDM. Human insulin does not normally cross the placenta, though antibody bound animal insulin has been reported to do so. ${ }^{35}$ However, it has been shown by ${ }^{36}$ Jovanovic that it is maternal glucose control, rather than maternal anti-insulin antibody levels which influence birthweight. ${ }^{36}$ Human insulin is considered safe in pregnancy as years of experience has not suggested an increase in fetal complications as a consequence of its use.

There is now increasing evidence that the newer rapid acting insulin analogs lispro and aspart are also safe in pregnancy, and indeed, they are commonly used. Although there was an initial small uncontrolled report which suggested that Lispro may have teratogenic effects when used in type 1 diabetic pregnancy, ${ }^{37}$ this has not been borne out in subsequent studies. No increase in pregnancy complications have been found in observational studies where lispro was used, in either women with $\mathrm{GDM}^{38,43}$ or pre-existing diabetes. ${ }^{38-43}$ There are few reports regarding the use of aspart in pregnancy. However, a large randomized controlled trial comparing aspart with regular human insulin in 322 pregnant women with type 1 diabetes has been performed. ${ }^{44}$ Comparable birth outcomes were found between the two arms, suggesting that aspart is as safe and effective as human insulin.

With respect to GDM, there have been several small randomized studies comparing the use of rapid acting insulin analogues with regular insulin. They have all demonstrated that the rapid acting analogues are as effective as regular insulin in the treatment of GDM, with comparable, if not favorable, outcomes (Table 3). In one study, aspart was detected in the cord blood for one subject. ${ }^{45}$ However, as it was not detected in other subjects, the authors postulated that this was due to the disruption of the uterine-placental barrier during delivery, when the mother had been receiving an aspart infusion. As yet there have been no reports of the use of glulisine in pregnancy.

Data regarding the long-acting insulin analogs are less clear than for rapid-acting analogs. There are a number of case reports and small case series of glargine being utilized without the development of pregnancy complications. The majority of these have been in patients with type 1 diabetes. There are also data from a total of 48 women with GDM. ${ }^{46,47}$ To date no randomized controlled studies have been published. Concerns have been expressed about the use of glargine in pregnancy, because of its potential effect on mitogenesis, mediated by its high affinity to the IGF-1 receptor, which is six times that of natural insulin ${ }^{48,49}$ Whilst insulin detemir has a lower binding affinity to the IGF-1 receptor than natural insulin, there is even less information regarding its use in pregnancy.

Long-acting insulin analogs, particularly glargine, are increasingly being used in women with type 1 diabetes, and they are often continued through the pregnancy. Although their safety has not been proven, it is often rationalized that a change in the basal insulin will result in deterioration in glycemic control, and therefore the risk of continuing glargine is less than the risk from changing insulins. However, until their safety in pregnancy can be clearly established, the initiation of long-acting insulin analog therapy in women with GDM cannot be recommended.

Table 2 Recommended glucose targets

\begin{tabular}{llll}
\hline & Fasting & I $\mathbf{~ h r}$ postprandial & $\mathbf{2}$ hr postprandial \\
\hline ADA & 5.8 & 8.6 & 7.2 \\
ADIPS & 5.5 & 8.0 & 7.0 \\
CDA & 5.3 & 7.8 & 6.7 \\
\hline
\end{tabular}

Abbreviations: ADA, American Diabetes Association;ADIPS, Australasian Diabetes in Pregnancy Society; CDA, Canadian Diabetes Association. 
Table 3 Randomized trials comparing treatment of GDM with rapid acting insulin analogs and regular human insulin

\begin{tabular}{|c|c|c|c|c|c|c|}
\hline \multirow[t]{2}{*}{ Author, year } & \multicolumn{3}{|c|}{ Subjects } & \multirow[t]{2}{*}{ Effect on $\mathrm{Hb}_{\mathrm{Alc}}$} & \multirow[t]{2}{*}{ Effect on hypos } & \multirow[t]{2}{*}{ Other comments } \\
\hline & Lispro & Aspart & Regular & & & \\
\hline Jovanovic et al $1999^{50}$ & 19 & - & 23 & $\begin{array}{l}\text { Lower } 3 \mathrm{rd} \\
\text { trimester } \mathrm{Hb}_{\mathrm{Alc}} \\
\text { with Lispro }\end{array}$ & $\begin{array}{l}\text { Fewer hypos with } \\
\text { lispro }\end{array}$ & $\begin{array}{l}\text { Less I hr postprandial } \\
\text { hyperglycemia with lispro }\end{array}$ \\
\hline Mecacci et al $2003^{51}$ & 25 & - & 24 & Not reported & Not reported & $\begin{array}{l}\text { I hr postprandial glucose } \\
\text { higher with regular insulin }\end{array}$ \\
\hline Pettitt et al $2007^{45}$ & - & 14 & 13 & No difference & $\begin{array}{l}\text { More minor, but } \\
\text { not major hypos } \\
\text { with aspart }\end{array}$ & $\begin{array}{l}\text { Post-prandial glucose profile } \\
\text { and maternal c-peptide } \\
\text { lower with aspart }\end{array}$ \\
\hline Di Cianni et al $2007^{52}$ & 33 & 31 & 32 & No difference & $\begin{array}{l}\text { No subjects had } \\
\text { hypos }\end{array}$ & $\begin{array}{l}\text { I hr postprandial glucose and } \\
\text { birthweight higher in regular } \\
\text { insulin subjects }\end{array}$ \\
\hline
\end{tabular}

Abbreviation: $\mathrm{Hb}_{\mathrm{Alc}}$, glycated hemoglobin.

\section{Oral antidiabetic agents in gestational diabetes}

There is controversy regarding the use of oral hypoglycemic agents during pregnancy. Most government drug agencies have not approved their use in pregnancy, and major specialty diabetes organizations recommend that oral agents be ceased if the woman had been taking them pre-pregnancy ${ }^{53-55}$ There have now however, been randomized trials conducted with both glyburide and metformin which have not demonstrated short term harm to the pregnancy.

\section{Glyburide (Glibenclamide)}

American authors have stated that glyburide has replaced insulin as first line pharmacological treatment of GDM in many practices. ${ }^{56}$ This has largely occurred on the basis of a randomized controlled trial where 404 women with GDM were treated with glyburide (up to $20 \mathrm{mg} /$ day) or insulin ${ }^{57} \mathrm{In}$ this study, the level of glycemic control achieved was the same in both groups (mean glucose concentration during treatment with glyburide $5.9 \pm 0.9 \mathrm{mmol} / \mathrm{L}$ compared to $5.9 \pm 1.0 \mathrm{mmol} / \mathrm{L}$ in insulin group). Only $4 \%$ of women treated with glyburide achieved inadequate control and required a switch to insulin. No differences in large for gestational age, macrosomia, neonatal hypoglycemia, admission to neonatal intensive care, or fetal anomalies were observed. The incidence of maternal hypoglycemia was lower in the glyburide group ( $2 \%$ vs $20 \%$ ).

Additionally, a number of nonrandomized or retrospective studies examining the treatment of GDM with glyburide have been reported (Table 4). In general, these indicate that glyburide is effective in achieving glycemic control in the majority of patients. Most, but not all, suggest that glyburide is as safe as insulin for the fetus. A meta-analysis which included the above studies as well as others examining women with pre-existing diabetes, with 745 glyburide exposed pregnancies and 637 treated with insulin, has been performed ${ }^{65}$ This study found that glyburide did not increase the risk of macrosomia, large for gestational age, or neonatal hypoglycemia, but did not examine more serious consequences such as perinatal mortality or congenital anomalies. Several studies have examined factors which predict failure of glyburide to achieve adequate glycemic control. Higher glucose levels, either in the glucose tolerance test upon which GDM was diagnosed, or on self-monitoring, and early dietary failure have been found to be associated with glyburide failure. ${ }^{60,58}$ These findings lead to the logical conclusion that subjects with more severe GDM are more likely to require insulin.

Further evidence supporting the safety of glyburide for the fetus comes from a study using an in vitro perfusion, where it was not found to cross the placenta in significant amounts. ${ }^{66}$ However, another in vitro study has found transplacental transfer of glyburide.$^{67}$ In the Langer randomized controlled trial, glyburide was not detected in the cord blood of the neonates and cord insulin levels were similar between the two groups. ${ }^{57}$

\section{Metformin}

A number of studies have provided conflicting information regarding the safety of metformin use in type 2 diabetic pregnancy ${ }^{68-70}$ There are studies which have used metformin during pregnancy in women with polycystic ovary syndrome, without any noticeable adverse effects on the fetus. ${ }^{71}$ There are few publications of its use in GDM, and these are dominated by the Metformin in Gestational Diabetes (MiG) Study.

The MiG Study randomized 751 women with GDM to treatment with insulin or metformin. ${ }^{72}$ The women in the metformin arm were treated with supplemental insulin if the maximal dose of metformin, $2500 \mathrm{mg}$ daily, failed to meet 


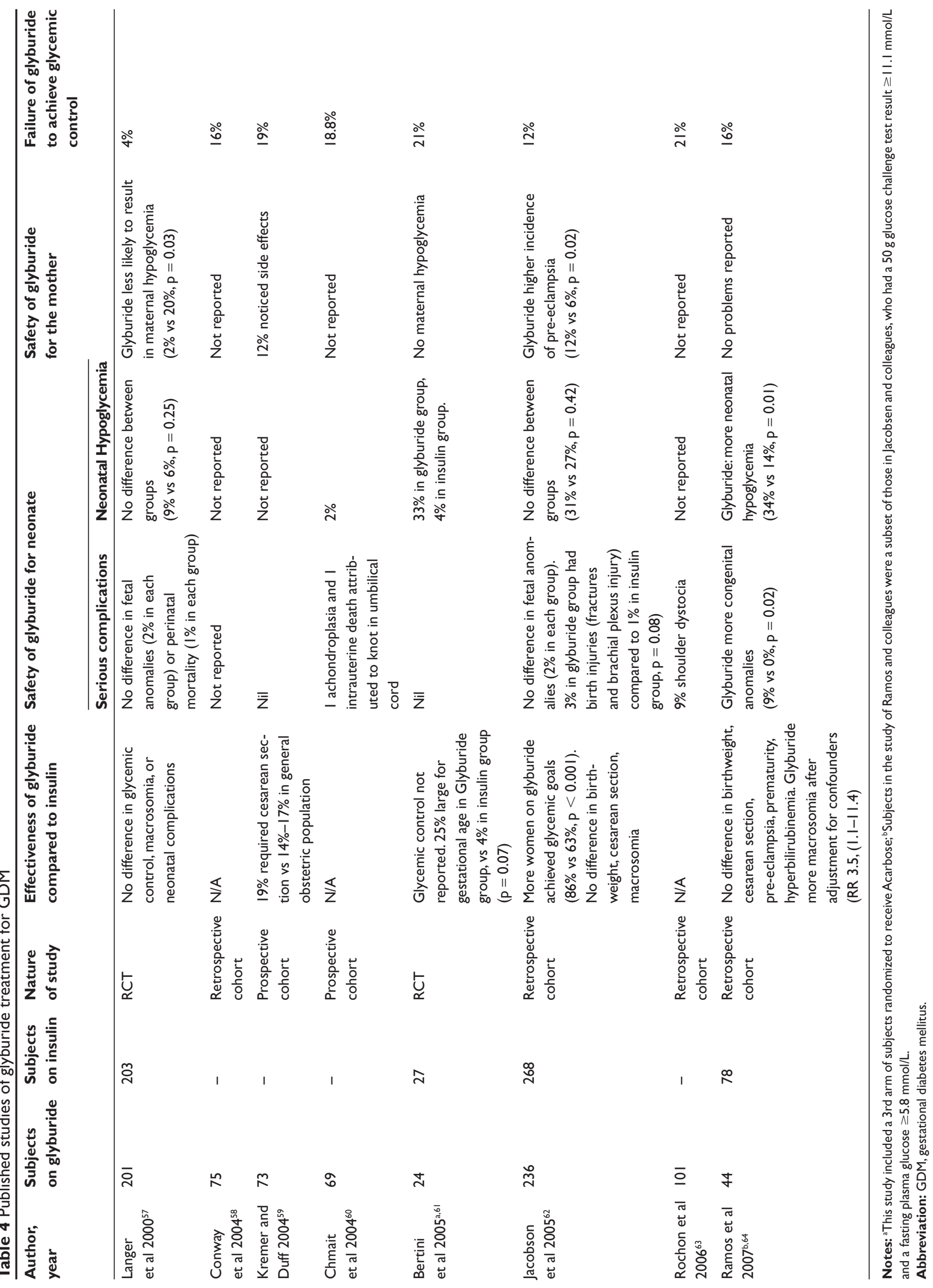


the glucose targets. The primary outcome variable was a composite of neonatal hypoglycemia, respiratory distress, need for phototherapy, birth trauma, Apgar score less than 7 , or prematurity. There was no difference in the primary outcome between the two groups (metformin 116 [32\%] events, insulin 119 events [32.2\%], RR 1.0 [0.9-1.1], p = 0.95). Interestingly fetal death and malformations were not a component of the primary outcome; however, 19 events in the metformin group were classified as serious fetal or neonatal adverse events (including 11 congenital anomalies) compared to 23 events in the insulin arm (including 18 congenital anomalies and one fetal death). None of these events were adjudged by the data and safety monitoring committee to be treatment related and there were no serious adverse events associated with the use of metformin. Additionally, more women using metformin indicated that their treatment was acceptable compared to those on insulin. From these results, the authors have suggested that metformin is a safe and effective treatment for GDM.

Several small studies comparing metformin to insulin for the treatment of GDM have also been performed (Table 5). Two have concluded that metformin is as effective as insulin for glycemic control in GDM, and that it is safe. However, one study, a randomised controlled trial, was underpowered to realistically address the effectiveness and safety of metformin in GDM. ${ }^{73}$ In another study, a retrospective case control study, subjects treated with insulin had a greater degree of initial glucose intolerance, so the comparison was of limited validity. ${ }^{74} \mathrm{~A}$ third study comprised a retrospective cohort which included a mixture of both GDM and women with Type 2 diabetes seen from 1966-1991. It found an increase in stillbirth and perinatal mortality, as well as pre-eclampsia amongst those treated with metformin, compared to women treated with insulin or sulphonylureas. However, as there was no evaluation of glycemic control early in pregnancy, and more women on metformin had pre-existing type 2 diabetes, the groups do not appear to be well matched. It is quite possible that the adverse findings in this study are due to more women in the metformin group having a greater severity of hyperglycemia early in the pregnancy.

\section{Long-term concerns regarding glyburide and metformin therapy for GDM}

Although the above randomized trials have demonstrated noninferiority of glyburide and metformin in achieving glycemic control, and satisfactory birth outcomes compared to insulin therapy, concerns must remain as long-term issues have not yet been addressed. Repeated episodes of GDM are associated with the earlier development of diabetes, and this has been postulated to be due to the increased stress that the $\beta$-cells are exposed to with each pregnancy. ${ }^{75}$ By treating the mother with glyburide, it is possible that this accentuates $\beta$-cell stress and accelerates their decline, whereas insulin therapy would conversely provide a degree of relief to the $\beta$-cells. Therefore glyburide has the potential to result in earlier development of maternal diabetes, and long-term follow-up of the mothers are needed to alleviate this concern.

In contradistinction, metformin reduces insulin resistance and hepatic gluconeogenesis, which theoretically would be beneficial for the preservation of $\beta$-cell function. In subjects with type 2 diabetes, the ADOPT Study has demonstrated that metformin is superior to glyburide in this regard. ${ }^{76}$ As there is transplacental passage of metformin, ${ }^{77,78}$ its effect on fetal insulin resistance might even provide further benefit in light of data of insulin resistance and insulin secretory defects in offspring of diabetic pregnancies. ${ }^{19}$ However, any pharmacological agent which crosses the placenta must be viewed with caution as there always remains the possibility of unexpected long-term effects. Metformin alters gene expression in mice livers and has been demonstrated to have an antiproliferative effect through reductions in cyclin D1 and activation of AMP kinase. ${ }^{79}$ The programming and developmental effects of these on a fetus are unknown. Furthermore, metformin can promote the development of lactic acidosis, which surely must be a concern in situations of fetal distress. Whilst 18-month follow-up data on 126 offspring of women with polycystic ovary syndrome treated with metformin during pregnancy have not revealed any deficiencies in growth or motor-social development, this may be too short a time frame for potential programming effects of metformin to become evident. ${ }^{80}$

In view of the above concerns regarding the potential of glyburide and metformin to have long-term effects on the mother and child, I would recommend caution with their use in the treatment of GDM. A subgroup of infants from the MIG Study are currently being followed up. ${ }^{72}$ It may be circumspect to await the findings from this follow-up study before metformin can be considered safe for the routine treatment of GDM.

\section{Other oral antidiabetic agents for gestational diabetes}

There is one study which randomized women with GDM to treatment with insulin, glyburide, or acarbose. ${ }^{61}$ Forty two percent of the acarbose subjects failed to achieve adequate 


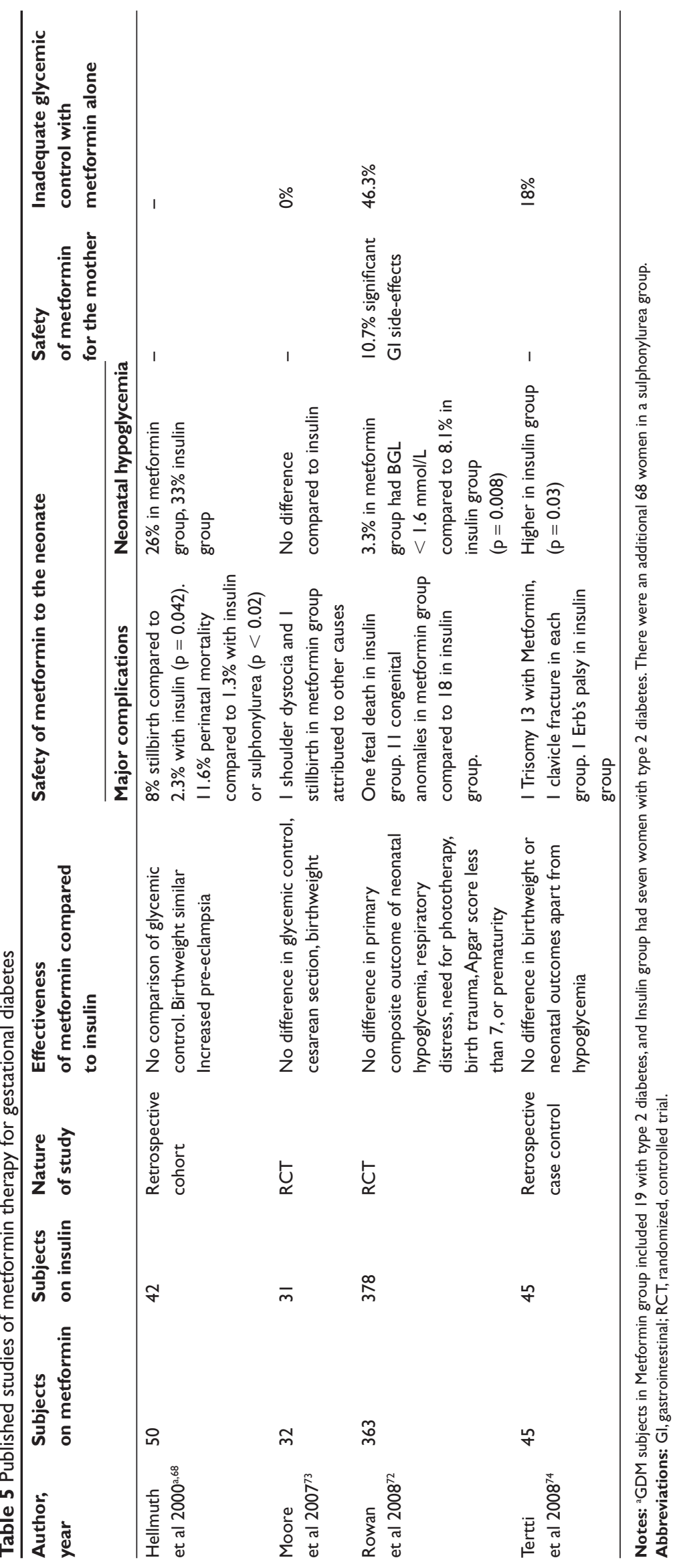


glycemic control and ultimately required insulin therapy. The incidence of large for gestational age was $10.5 \%$, compared to $3.7 \%$ for insulin and $25 \%$ for glyburide $(p=0.07)$. The rate of neonatal hypoglycemia $(5.3 \%)$ was similar to insulin $(3.7 \%)$, but lower than glyburide $(33 \%)(p=0.006)$. Whilst this study is inadequately powered to demonstrate safety of acarbose, it is not absorbed from the gut, and therefore would be unlikely to affect the fetus. However it is of low potency and insulin therapy will often need to be introduced. Furthermore, the high frequency of gastrointestinal side effects experienced by people with type 2 diabetes suggests that any future role of acarbose, even if subsequent studies confirm safety, will be limited.

There are no studies using glitazones in pregnancy. Transplacental transfer occurs, ${ }^{67,81}$ and until studies demonstrating safety are performed, they should be avoided in pregnancy.

\section{Evidence that treatment of gestational diabetes improves pregnancy outcomes}

The strongest evidence that treatment of GDM is of benefit comes from the Australian Carbohydrate Intolerance Study (ACHOIS) in Pregnant Women. ${ }^{82}$ In this randomized controlled trial, 1000 women fulfilling the 1985 WHO criteria for "gestational glucose intolerance" were recruited. These subjects had a fasting glucose up to $7.7 \mathrm{mmol} / \mathrm{dl}$ and a 2 hour level between $7.8 \mathrm{mmol} / \mathrm{L}$ and $11.1 \mathrm{mmol} / \mathrm{dl}$. They were randomized to receive treatment for GDM, including dietary advice, blood glucose monitoring, and insulin as required, or standard pregnancy care. Those receiving standard care were unaware that they had GDM. In the treatment group, the aim was to maintain a fasting glucose level of $<5.5 \mathrm{mmol} / \mathrm{L}$, and 2 hour post-prandial reading $<7.0 \mathrm{mmol} / \mathrm{L}$. With this, there was a $1 \%$ incidence of serious perinatal outcomes (death, shoulder dystocia, fracture, and nerve palsy) compared to $4 \%$ amongst women provided with standard pregnancy care only (adjusted risk reduction 0.33, p =0.01). Fewer neonates in the treatment group were large for gestational age, and there was no difference in the incidence of small for gestational age infants. There was no difference in the rate of cesarean section. Preeclampsia occurred less frequently in the intervention group ( $12 \%$ vs $18 \%$, adjusted risk reduction $0.7, p=0.02$ ). One other important finding of this study was that intensively treated women had better quality of life and lower rates of depression.

Prior to ACHOIS, a large number of other studies had been performed to ascertain if treatment of GDM is of benefit.
These studies were largely retrospective, unrandomized, or lacked power to detect differences in serious adverse perinatal outcomes and will not be listed here. However, one large retrospective cohort study of 116,303 pregnancies, merits discussion. Because of changes in the diagnostic criteria for GDM over the years, Beischer (1996) was able to examine perinatal mortality amongst women who would have been diagnosed as having GDM by contemporary criteria, but were not considered to have GDM at the time, and were therefore untreated. The perinatal mortality rate was $2.6 \%$ in these women with 'mild GDM' in the 1970 s, compared to $0.7 \%$, in the $1980 \mathrm{~s}$ after routine treatment had been introduced for this group. Their perinatal mortality rate was 2.3 times that of women with normal glucose tolerance. In the 1980s, with routine treatment for women with mild GDM, their outcomes were not different to women with normal glucose tolerance. It therefore seems likely that the decreased mortality rate was at least in part a consequence of treatment of GDM, rather than only to other improvements in obstetric outcome.

\section{Post-partum management of gestational diabetes}

The medical management of gestational diabetes should not conclude with the delivery of the fetus. Although hyperglycemia usually resolves with the conclusion of the pregnancy, women who have had GDM are at high risk of developing diabetes later in life. Apart from the development of diabetes, women who have had GDM have an adverse cardiac risk profile, including the metabolic syndrome..$^{83,84}$ A higher prevalence of cardiovascular disease that occurs at a younger age, independent of the metabolic syndrome and type 2 diabetes has also been demonstrated. ${ }^{83}$

In view of the above, it is important that the woman who has had GDM receive counseling and support to reduce her long-term risk of diabetes. Screening for diabetes, at regular intervals, is recommended by a number of diabetes societies. ${ }^{4,85}$ This is important for the early diagnosis of diabetes, to facilitate the prevention of complications. Furthermore, if the woman is of reproductive age, the pre-pregnancy recognition of diabetes is vital so that early pregnancy conditions can be optimized to prevent diabetes fetopathy. Issues specific to pre-existing diabetes in pregnancy include tight glycemic control and adequate folate supplementation. ${ }^{53,54}$ Additionally, post partum evaluation and management of reversible cardiovascular risk factors such as smoking, obesity, hypertension, and hyperlipidemia should be undertaken.

There is evidence that lifestyle modification, aiming for a $5 \%-7 \%$ reduction in body weight, is effective in preventing 
or delaying the development of diabetes in people with impaired glucose tolerance. Both the Diabetes Prevention Program $^{86}$ and the Finnish Diabetes Prevention Study ${ }^{87}$ demonstrated this, with an intensive intervention including lifestyle coaches, strict supervised exercise regimes and caloric restriction. As $15 \%$ of the women in the Diabetes Prevention Program and Diabetes Prevention Study had GDM, similar measures should be recommended to women after they have had GDM. However, it is unclear if less intensive interventions can be effective in this population. To date, small short-term studies focusing on dietary counseling alone, or a combination of behavioral strategies with weekly exercise classes, have not demonstrated an improvement in glucose tolerance. ${ }^{88,89}$ In part, this is probably due to the real life challenges of maintaining motivation for healthy lifestyle change amongst young women at a time that they are having to deal with young children, return to work, and further education. Nonetheless, there are undisputed benefits to healthy eating and regular physical activity so these activities should be encouraged.

\section{Summary and conclusions}

Gestational diabetes is a common disorder which in the majority of cases, should initially be managed by dietary measures. These include a restriction in fat and simple carbohydrate intake, regular distribution of meals, carbohydrate foods favoring those with low glycemic index, and caloric restriction for those who are obese. Moderate physical activity should be encouraged. Fasting and post-prandial glucose testing is necessary for monitoring and guidance of therapy.

Where dietary measures are inadequate to achieve glycemic targets, insulin should be introduced. Insulin is still the mainstay of pharmacological treatment of GDM, and this is ideally administered in a basal bolus regimen. The rapid acting analogs lispro and aspart are considered safe, but the safety of the long-acting analogs are yet to be determined. Whilst there are studies demonstrating short-term safety of glyburide and metformin during pregnancy, I suggest that they be reserved for situations where implementation of insulin therapy is impractical or not possible. After all, we know that insulin therapy is safe and usually effective. ACHOIS has shown that it is acceptable to the majority of women. By eschewing insulin, doctors may actually be treating their own perceived fear of injections, rather than providing the best therapy to the patient. Based on our current information, insulin is still the best option, with the least potential for long-term risk to the mother and child.
With good medical and obstetric care, the risks to the pregnancy should be minimal. However, a woman with GDM is a woman at high risk of future diabetes. Therefore after the pregnancy, healthy lifestyle measures should be encouraged to minimize the likelihood of developing diabetes, and regular screening for diabetes should be undertaken.

\section{Disclosure}

The author reports no conflicts of interest in this work.

\section{References}

1. Metzger BE. 1990 overview of GDM. Accomplishments of the last decade-challenges for the future. Diabetes. 1991;40(Suppl 2):1-2.

2. Cheung NW, Byth K. The population health significance of gestational diabetes. Diabetes Care. 2003;26:2005-2009.

3. Catalano PM, Tyzbir ED, Wolfe RE, et al. Carbohydrate metabolism during pregnancy in control subjects and women with gestational diabetes. Am J Physiol. 1993;164(1 part 1):E60-E67.

4. American Diabetes Association. Gestational diabetes mellitus. Diabetes Care. 2004;27(Suppl 1):S88-S90.

5. Hedderson MM, Ferrara A. High blood pressure before and during early pregnancy is associated with an increased risk of gestational diabetes mellitus. Diabetes Care. 2008;31:2362-2367.

6. Langer O, Mazze R. The relationship between large-for-gestational age infants and glycemic control in women with gestational diabetes. $\mathrm{Am}$ J Obstet Gynecol. 1988;159:1478-1483.

7. Hod M, Merlob P, Friedman S, et al. Gestational diabetes mellitus: A survey of perinatal complications in the 1980s. Diabetes. 1991;40(Suppl 2):74-78

8. Ecker JL, Greenberg JA, Norwitz ER, et al. Birth weight as a predictor of brachial plexus injury. Obstet Gynecol. 1997;89:643-647.

9. Jang $\mathrm{HC}$, Cho HC, Min YK, et al. Increased macrosomia and perinatal morbidity independent of maternal obesity and advanced age in Korean women with GDM. Diabetes Care. 1997;20:1582-1588.

10. Persson B, Hanson U. Neonatal morbidities in gestational diabetes mellitus. Diabetes Care. 1998;21(Suppl 2):B79-B84.

11. Hapo Study Cooperative Research Group. Hyperglycaemia and adverse pregnancy outcomes. $N$ Eng J Med. 2008;358:1991-2002.

12. Sepe SJ, Connell FA, Geiss LS, et al. Gestational diabetes: Incidence, maternal characteristics, and perinatal outcome. Diabetes. 1985;34(Suppl 2):13-16.

13. Beischer NA, Wein P, Sheedy MT, et al. Identification and treatment of women with hyperglycaemia diagnosed during pregnancy can significantly reduce perinatal mortality rates. Aust NZ J Obstet Gynaecol. 1996;36:239-247.

14. Schaefer U, Songster G, Xiang A, et al. Congenital malformations in offspring of women with hyperglycemia first detected during pregnancy. Am J Obstet Gynecol. 1997;177:1165-1171.

15. Schmidt MI, Spichler ER, Duncan BB, et al. Gestational diabetes mellitus diagnosed with a 2-h 75-g oral glucose tolerance test and adverse pregnancy outcomes. Diabetes Care. 2001;24:1151-1155.

16. Pettitt DJ, Aleck KA, Baird HR, et al. Congenital susceptibility to NIDDM. Role of intrauterine environment. Diabetes. 1988; 37:622-628

17. Dabelea D, Knowler WC, Pettitt D. Effect of diabetes in pregnancy on offspring: Follow-up research in the Pima Indians. J Mat Fet Med. 1993;9:83-88.

18. Silverman BL, Rizzo T, Green OC, et al. Long-term prospective evaluation of offspring of diabetic mothers. Diabetes. 1991; 40(Suppl 2):121-125.

19. Sobngwi E, Boudou P, Mauvais-Jarvis F, et al. Effect of a diabetic environment in utero on predisposition to type 2 diabetes. Lancet. 2003;361:1862-1865. 
20. McLean M, Cheung NW, Chipps D. Mother to child transmission of diabetes mellitus: Does gestational diabetes program Type 2 diabetes in the next generation? Diabetic Med. 2006;23:1213-1215.

21. O'Sullivan JB. Diabetes mellitus after GDM. Diabetes. 1991; 29(Suppl 2):131-135.

22. Kim C, Newton K, Knopp R. Gestational diabetes and the incidence of type 2 diabetes. Diabetes Care. 2002;25:1862-1868.

23. Tseng $\mathrm{CH}$. Parental diabetes in Taiwanese diabetic women with and without previous gestational diabetes. Eur J Clin Invest. 2008;38:555-561.

24. Conway DL. Obstetric management in gestational diabetes. Diabetes Care, 2007;30(Suppl 2):S175-S179.

25. de Veciana M; Major CA, Morgan MA, et al. Postprandial versus preprandial blood glucose monitoring in women with gestationa diabetes mellitus requiring insulin therapy. $N$ Eng J Med. 1995;333: 1237-1241.

26. Kjos SL, Schaefer-Graf U, Sardesi S, et al. A randomised controlled trial using glycemic plus ultrasound parameters versus glycemic parameters to determine insulin therapy in gestational diabetes with fasting hyperglycemia. Diabetes Care. 2001;24:1904-1910.

27. Reader D, Splett P, Gunderson EP, et al. Impact of gestational diabetes mellitus nutritional practice guidelines implemented by registered dietitians on pregnancy outcomes. J Am Diet Assoc. 2006; 106:1426-1433.

28. Major CA, Henry MJ, de Veciana M, et al. The effects of carbohydrate restriction in patients with diet-controlled gestational diabetes. Obstet Gynecol. 1998;1:600-604.

29. Clapp JE. Maternal carbohydrate intake and pregnancy outcome. Proc Nutr Soc. 2002;61:45-50.

30. Moses RG, Luebcke M, Davis WS, et al. Effect of a low-glycemic-index diet during pregnancy on obstetric outcomes. Am J Clin Nutr. 2006;84:807-812.

31. Jovanovic-Peterson L, Durak EP, Peterson CM. Randomised trial of diet versus diet plus cardiovascular conditioning on glucose levels in gestational diabetes. Am J Obstet Gynecol. 1989;161:415-419.

32. Avery MD, Leon AS, Kopher RA. Effects of a partially home-based exercise program for women with gestational diabetes. Obstet Gynecol. 1997;89:10-15.

33. Brankston GN, Mitchell BF, Ryan EA. Resistance exercise decreases the need for insulin in overweight women with gestational diabetes mellitus. Am J Obstet Gynecol. 2004;190:188-193.

34. Nachum Z, Ben-Shlomo I, Weiner E, et al. Twice daily insulin versus four times daily insulin dose regimens for diabetes in pregnancy: randomised controlled trial. Br Med J. 1999;319:1223-1227.

35. Menon RK, Cohen RM, Sperling MA, et al. Transplacental passage of insulin in pregnant women with insulin-dependent diabetes mellitus: its role in fetal macrosomia. $N$ Eng J Med. 1990;323:309-315.

36. Jovanovic L, Kitzmiller JL, Peterson CM. Randomized trial of human versus animal species insulin in diabetic pregnant women: improved glycemic control, not fewer antibodies to insulin, influences birthweight. Am J Obstet Gynecol. 1992;167:1325-1330.

37. Diamond TD, Kormas N. Possible adverse fetal effect of insulin lispro. N Engl J Med. 1997;337:1009-1010.

38. Bhattacharyya A, Brown S, Hughes S, et al. Insulin lispro and regular insulin in pregnancy. Q J Med. 2001;94:255-260.

39. Persson B, Swahn ML, Hjertberg R, et al. Insulin lispro therapy in pregnancies complicated by type 1 diabetes mellitus. Diab Res Clin Pract. 2002;58:115-121.

40. Masson EA, Patmore JE, Brash PD, et al. Pregnancy outcome in Type 1 diabetes mellitus treated with insulin lispro (Humalog). Diabetic Med. 2003;20:46-50.

41. Garg SK, Frias JP, Anil S, et al. Insulin lispro therapy in pregnancies complicated by type 1 diabetes: glycemic control and maternal and fetal outcomes. Endocr Pract. 2003;9:187-193.

42. Wyatt JW, Frias JL, Hoyne HE, et al. Congenital anomaly rate in offspring of mothers with diabetes treated with insulin lispro during pregnancy. Diabet Med. 2005;22:803-807.
43. Aydin Y, Berker D, Direktor N, et al. Is insulin lispro safe in pregnant women: Does it cause any adverse outcomes on infants or mothers. Diab Res Clin Pract. 2008;80:444-448.

44. Hod M, Damm P, Kaaja R, et al. Fetal and perinatal outcomes in type 1 diabetes pregnancy: randomised study comparing insulin aspart with human insulin in 322 subjects. Am J Obstet Gynecol. 2008;198:e1-e7.

45. Pettitt DJ, Ospina P, Howard C, et al. Efficacy, safety and lack of immunogenicity of insulin aspart compared with regular human insulin for women with gestational diabetes. Diabetic Med. 2007;24:1129-1135.

46. Graves DE, White JC, Kirk JK. The use of glargine insulin with gestational diabetes mellitus. Diabetes Care. 2006;29:471-472.

47. Price N, Bartlett C, Gillmer MD. Use of insulin glargine during pregnancy: A case-control pilot study. Br J Obstet Gynecol. 2007; 114:453-457.

48. Hirsch I. Insulin analogs. N Eng J Med. 2005;352:174-183.

49. Jovanovic L, Pettitt DJ. Treatment with insulin and its analogs in pregnancies complicated by diabetes. Diabetes Care. 2007; 30(Suppl 2):S220-S224.

50. Jovanovic L, Gutierrez M, Ilic S, et al. Metabolic and immunologic effects of insulin lispro in gestational diabetes. Diabetes Care. 1999;22:1422-1427.

51. Mecacci F, Carignani L, Cioni R, et al. Maternal metabolic control and perinatal outcome in women with gestational diabetes treated with regular or lispro insulin: comparison with non-diabetic pregnant women. Eur J Obstet Gynecol. 2003;111:19-24.

52. Di Cianni G, Volpe L, Ghio A. Maternal metabolic control and perinatal outcome in women with gestational diabetes mellitus treated with lispro or aspart insulin. Diabetes Care. 2007;30:e11

53. McElduff A, Cheung NW, McIntyre HD, et al. The Australasian Diabetes in Pregnancy Society consensus guidelines for the management of type 1 and type 2 diabetes in relation to pregnancy. Med J Aust. 2005; 183:373-377.

54. Kitzmiller JL, Jovanovic LB, Block JM, et al. Managing pre-existing diabetes for pregnancy. Diabetes Care. 2008;31:1060-1079.

55. Canadian Diabetes Association 2008. Clinical Practice Guidelines for the Prevention and Management of Diabetes in Canada. Gestational diabetes mellitus. Diabetes and Pregnancy. Can J Diabetes. 2008; 32(Suppl 1):S168-S180.

56. Ecker JL, Greene MF. Gestational diabetes - Setting limits, exploring treatments. N Eng J Med. 2008;358:2061-2062.

57. Langer O, Conway DL, Berkus MD, et al. A comparison of glyburide and insulin in women with gestational diabetes mellitus. $N$ Eng $J$ Med. 2000;343:1134-1138.

58. Conway DL, Gonzales O, Skiver D. Use of glyburide for the treatment of gestational diabetes: The San Antonio experience. J Mat Fet Neonat Med. 2004;15:51-55.

59. Kremer CJ, Duff P. Glyburide for the treatment of gestational diabetes. Am J Obstet Gynecol. 2004;190:1438-1439.

60. Chmait R, Dinise T, Moore T. Prospective observational study to examine predictors of glyburide success in women with gestational diabetes. J Perinatol. 2004;24:617-622.

61. Bertini AM, Silva JC, Taborda W. Perinatal outcomes and the use of oral hypoglycemic agents. J Perinat Med. 2005;33:519-523.

62. Jacobson GF, Ramos GA, Ching JY, et al. Comparison of glyburide and insulin for the management of gestational diabetes in a large managed care organization. Am J Obstet Gynecol. 2005;193:118-124.

63. Rochon M, Rand L, Roth L, et al. Glyburide for the management of gestational diabetes: Risk factors predictive of failure and associated outcomes. Am J Obstet Gynecol. 2006;195:1090-1094.

64. Ramos GA, Jacobson GF, Kirby RS, et al. Comparison of glyburide and insulin for the management of gestationial diabetes with markedly elevated oral glucose challenge test and fasting hyperglycemia. J Perinatol. 2007;27:262-267.

65. Moretti ME, Rezvani M, Koren G. Safety of glyburide for gestational diabetes: A meta-analysis of pregnancy outcomes. Ann Pharmacother 2008;42:483-489. 
66. Elliott BD, Langer O, Schenker S, et al. Insignificant transfer of glyburide occurs across the human placenta. Am J Obstet Gynecol. 1991;165:807-812.

67. Nanovskaya TN, Patrikeeva S, Hemauer S, et al. Effect of albumin on transplacental transfer and distribution of rosiglitazone and glyburide. J Mat Fet Neonat Med. 2008;21:197-207.

68. Hellmuth E, Damm P, Molsted-Pedersen L. Oral hypoglycaemic agents in 118 diabetic pregnancies. Diabet Med. 2000;17:507-511.

69. Coetzee EJ, Jackson WPU. The management of non-insulin dependent diabetes during pregnancy. Diabetes Res Clin Prac. 1985;1:281-287.

70. Hughes RCE, Rowan JA. Pregnancy in women with type 2 diabetes: who takes it and what is the outcome. Diabet Med. 2006;23:318-322.

71. Glueck CJ, Wang P, Goldenberg N, et al. Pregnancy outcomes ampong women with polycystic ovary syndrome treated with metformin. Hum Reproduct. 2002;17:2858-2864.

72. Rowan JA, Hague WM, Gao W, et al. Metformin versus insulin for the treatment of gestational diabetes. $N$ Eng $J \mathrm{Med}$. 2008;358:2003-2015.

73. Moore LE, Briery CM, Clokey D. Metformin and insulin in the management of gestational diabetes mellitus. J Repro Med. 2007;52:1011-1015.

74. Tertti K, Ekblad U, Vahlberg T, et al. Comparison of metformin and insulin in the treatment of gestational diabetes: A retrospective, case control study. Rev Diabet Stud. 2008;5:95-101.

75. Peters RK, Kjos SL, Xiang A, et al. Long-term diabetogenic effect of single pregnancy in women with previous gestational diabetes mellitus. Lancet. 1996;347:227-230.

76. Khan SE, Haffner SM, Heise MA, et al. Glycemic durability of rosiglitazone, metformin, or glyburide monotherapy. $N$ Eng J Med. 2007;355:2427-2443.

77. Vanky E, Zahlsen K, Spigset O, et al. Placental passage of metformin in women with polycystic ovary syndrome. Fertil Steril. 2005;83:1575-1578.

78. Hague WM. Metformin crosses the placenta: A modulator for fetal insulin resistance? Rapid response letter. Dec 4, 2003. Br Med J. Cited Sept 20, 2008. Available from: http://www.bmj.com/cgi/ eletters $/ 327 / 7420 / 880$
79. Zakikhani M, Dowling R, Fantus IG. Metformin is an AMP kinase-dependent growth inhibitor for breast cancer cells. Cancer Res. 2006;66:10269-10273.

80. Glueck CJ, Goldenberg N, Pranikoff J, et al. Height, weight and motorsocial development during the first 18 months of life in 126 infants born to 109 mothers with polycystic ovary syndrome who conceived on and continued metformin through pregnancy. Hum Reproduct. 2004; 19:1323-1330.

81. Chan LYS, Yeung JHK, Lau TK. Placental transfer of rosiglitazone in the first trimester of human pregnancy. Fert Steril. 2005;83:955-958.

82. Crowther CA, Hiller JE, Moss JR, et al. Effect of treatment of gestational diabetes on pregnancy outcomes. $N$ Eng $\mathrm{J}$ Med. 2005;352:2477-2486

83. Carr DB, Utzschneider KM, Hull RL, et al. Gestational diabetes mellitus increases the risk of cardiovascular in women with a family history of type 2 diabetes. Diabetes Care. 2006;29:2078-2083.

84. Lauenborg, J, Mathiesen E, Hansen T, et al. The prevalence of the metabolic syndrome in a Danish population of women with previous gestational diabetes mellitus is three-fold higher than in the general population. J Clin Endocrinol Metabi. 2005;90:4004-4010.

85. Simmons D, Walters B, Wein P, et al. Guidelines for the management of gestational diabetes mellitus revisited. Med J Aust. 2002;176:352.

86. Diabetes Prevention Program Research Group. Reduction in the incidence of type 2 diabetes with intensive intervention or metformin. N Eng J Med. 2002;346:393-403.

87. Tuomilehto J, Lindstrom J, Eriksson J, et al. Prevention of type 2 diabetes mellitus by changes in lifestyle among subjects with impaired glucose tolerance. $N$ Eng J Med. 2001;344:1343-1350.

88. Wein P, Beischer N, Harris C, et al. A trial of simple versus intensified dietary modification for prevention of progression to diabetes mellitus in women with impaired glucose tolerance. Aust NZJ Obstet Gynaecol. 1999;39:162-166.

89. Cheung NW, Smith BJ, Henriksen H, et al. A group-based healthy lifestyle program for women with previous gestational diabetes. Diab Res Clin Pract. 2007;77:333-334. 